\title{
Design and Simulation of a PID Controller Based on Fuzzy Control
}

\author{
Chenbin Wu, Haiming Li, Lei Wu \\ School of Computer and Information Engineering, Shanghai University of Electric Power, Shanghai, China \\ zjxulhm@163.com
}

\begin{abstract}
According to the fuzzy control theory, the paper describes the principle and feature of the fuzzy control by fuzzy control having strong robustness in allusion to the control system which has the characteristics of pure hysteresis and unprecise parameter time-variance and model. On this basis, it conducts the design and algorithm of the fuzzy controller. And it emulates the related project content by the use of Simulink software package of MATLAB in order to test and verify the availability of the project. Besides, in this paper, in order to deal with the delay lag link, deviation and deviation change rate are taken as inputs, a fuzzy inference method is utilized to optimize the traditional PID control, and the controller is designed and simulated with MATLAB. Good control performance can be acquired from the simulation result, the fuzzy PID controller improves the dynamic and static performance of the system. Combining the fuzzy control and PID control together can get their good qualities, which also has good practical significance and research value.
\end{abstract}

Keywords- Fuzzy control; PID control; Simulation modeling; Delay lag link; Fuzzy PID Controller

\section{INTRODUCTION}

As a kind of intelligent control method, fuzzy control is used to solve complex nonlinear system and some other system which is difficult to establish mathematical model, in addition, it is always applied to control problem of multiple input multiple output system which is unable to determine internal disturbance. Zadeh fuzzy set theory is the basis of fuzzy control[1], besides, the multivalue factors of fuzzy logic and artificial intelligence (the simplified reasoning principles) are applied in fuzzy control to simulate human thinking and reaction [2].

\section{DESIGN OF FUZZY PID CONTROLLER}

\section{A. Structure of Fuzzy PID Controller}

A serious of languages which come from expert's knowledge are used to describe and characterize the fuzzy system, and the control rules are determined by the practical experience and knowledge of the operators or experts. Meanwhile these rules could be adjusted in the process of actual operation constantly. The form of fuzzy control rules of fuzzy control system is shown as follow:

$$
\text { If } \mathrm{E}=A_{i} \text {, and } \mathrm{EC}=B_{j} \text {, then } \mathrm{U}=C_{i j} \text {. }
$$

In $(1), i=1,2,3, \cdots \cdots, m-1, m$ and $j=1,2, \cdots \cdots, n-1, n$. E represents the deviation variables and $A_{i}$ is the language variables of the deviation variables; EC represents the deviation change rate and $B_{j}$ is the language variables of deviation change rate variables; $U$ represents the output control variables and $C_{i j}$ is the language variables of output control variables refer to $A_{i}$ and $B_{j}$. Finally we can get the controlled variables by the center of gravity method which is used with Max-Min Algorithm to defuzzy output $U$ solution in order to produce accurate physical quantities.

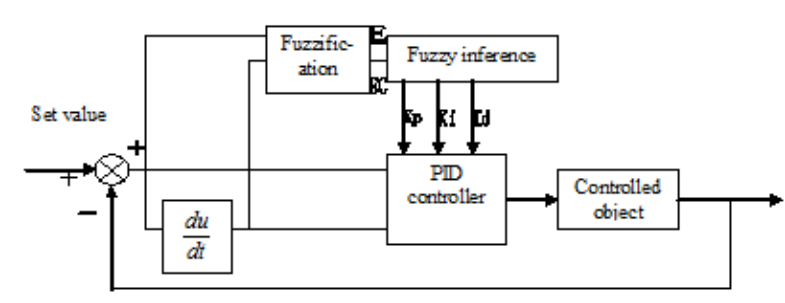

Figure 1. Fuzzy PID controller structure chart.

\section{B. Rules of Fuzzy PID Controller}

The design of the control rules is the key of the design of fuzzy controller, and it always include three parts: choose the words which are set of input/output variables, define the fuzzy subsets of the fuzzy variables and establish the control rules of fuzzy controller [3]. The core of the fuzzy controller is fuzzy inference which is based on fuzzy language rules, and the basis of fuzzy logic reasoning is fuzzy knowledge base. If the fuzzy control method could be combined with the traditional PID control method, it would make the both sides play better, and it could access a wider practicability. The structure chart of fuzzy PID controller is shown in Figure 1. 
As for the concrete practice, according to the language variable deviation $\mathrm{E}$ and deviation change rate $\mathrm{EC}$, and the application of the fuzzy set theory combined with the experience of PID parameters adjustment, a set of fuzzy control rules under different conditions of $K_{p}, K_{i}, K_{d}$ is summarized. The $\{\mathrm{NB}, \mathrm{NM}, \mathrm{NS}, \mathrm{ZE}, \mathrm{PS}, \mathrm{PM}, \mathrm{PB}\}$ represent \{negative big, negative middle, negative small, zero, positive small, positive middle, positive big \} as shown in Table1, 2, and 3.

TABLE I. FUZZY CONTROL RULES FOR $K_{p}$

\begin{tabular}{cccccccc}
\hline PB & ZE & NS & NS & NM & NM & NB & NB \\
PM & ZE & ZE & NS & NM & NM & NM & NB \\
PS & PS & PS & ZE & NS & NS & NM & NM \\
ZE & PM & PS & PS & ZE & NS & NM & NM \\
NS & PM & PM & PM & PS & ZE & PS & NM \\
NM & PB & PB & PM & PM & PS & ZE & ZE \\
NB & PB & PB & PM & PM & PS & PS & ZE \\
\hline
\end{tabular}

TABLE II. FUZZY CONTROL RULES FOR $K_{i}$

\begin{tabular}{cccccccc}
\hline Ki & NB & NM & NS & ZE & PS & PM & PB \\
\hline PB & ZE & ZE & PS & PM & PB & PB & PB \\
PM & ZE & ZE & PS & PM & PM & PB & PB \\
PS & NS & NS & ZE & PS & PS & PM & PM \\
ZE & NM & NS & NS & ZE & PS & PS & PM \\
NS & NM & NM & NS & NS & ZE & PS & PS \\
NM & NB & NB & NM & NM & NS & ZE & ZE \\
NB & NB & NB & NB & NM & NM & ZE & ZE \\
\hline
\end{tabular}

TABLE III. FUZZY CONTROL RULES FOR $K_{d}$

\begin{tabular}{cccccccc}
\hline PB & PS & ZE & ZE & ZE & ZE & PB & PB \\
PM & NM & NS & NS & NS & ZE & PS & PS \\
PS & NB & NM & NS & NS & ZE & PS & PS \\
ZE & NB & NM & NM & NS & ZE & PS & PM \\
NS & NB & NB & NM & NS & ZE & PS & PM \\
NM & NS & NS & NS & NS & ZE & ZE & PM \\
NB & PS & PS & ZE & ZE & ZE & PB & PB \\
\hline
\end{tabular}
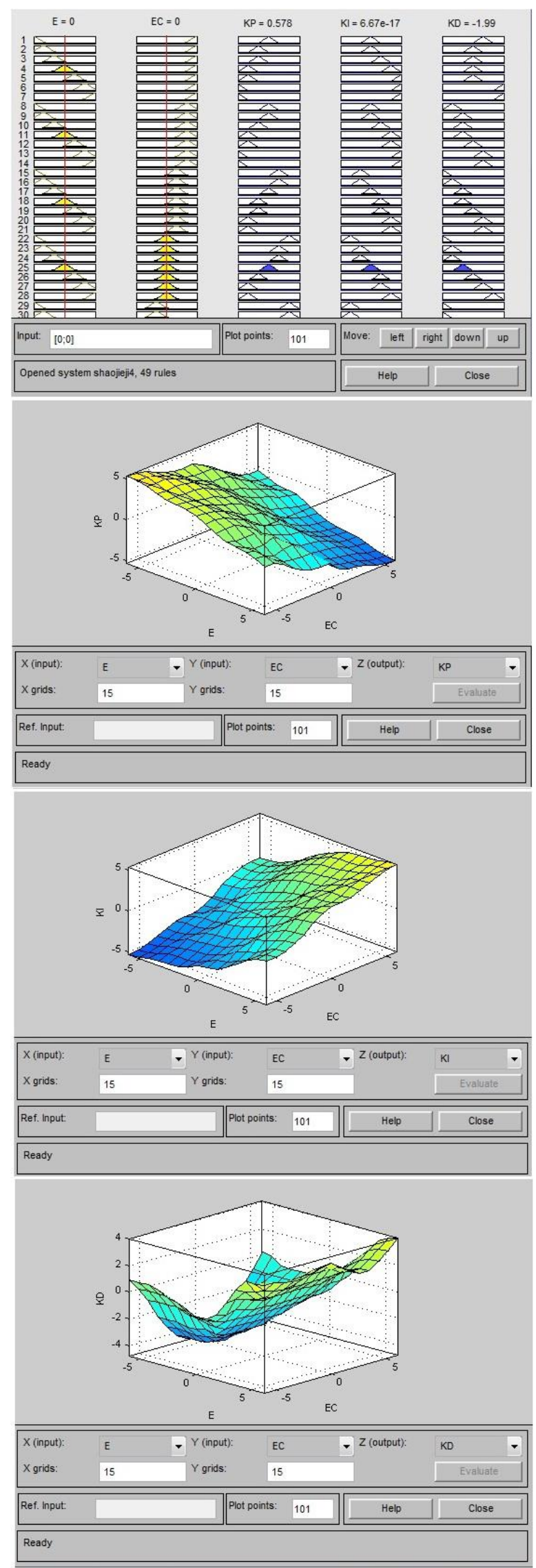

Figure 2. Rules and output surfaces 
By combining the above 3 tables together, 49 fuzzy control rules can be acquired. FIS (Fuzzy inference system) file comes from the rules in MATLAB. Open the surface view windows, rules and output surfaces for $K_{p}, K_{i}$, $K_{d}$ in universe are shown in Figure 2. Besides, all rules can be checked and changed by rule editor, as shown in Figure 3.

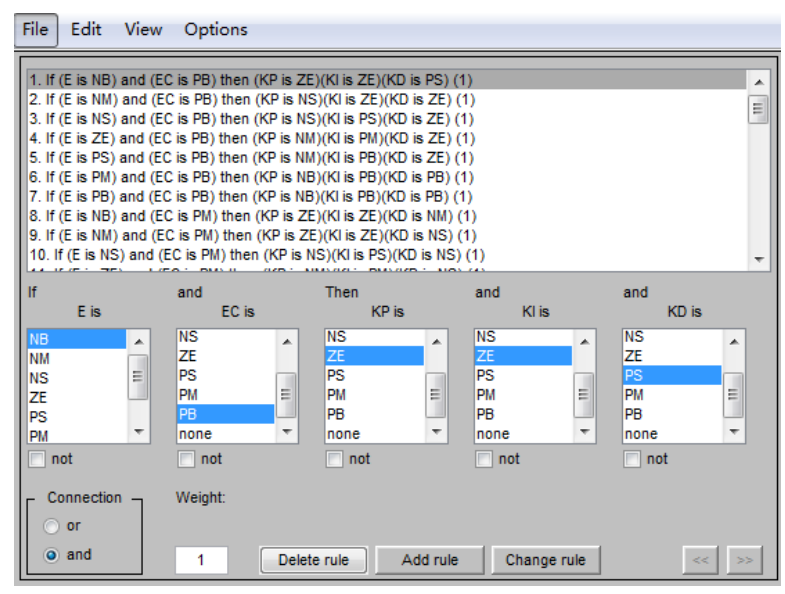

Figure 3. Rule editor

\section{MODELING AND SIMULATION OF FUZZY PID CONTROLLER}

\section{A. The simulation chart of system structure}

The object simulation mathematical model of this paper is shown as follow (pure hysteresis and delay lag link transfer function):

$$
G(s)=\frac{0.8}{1800 s+1}
$$

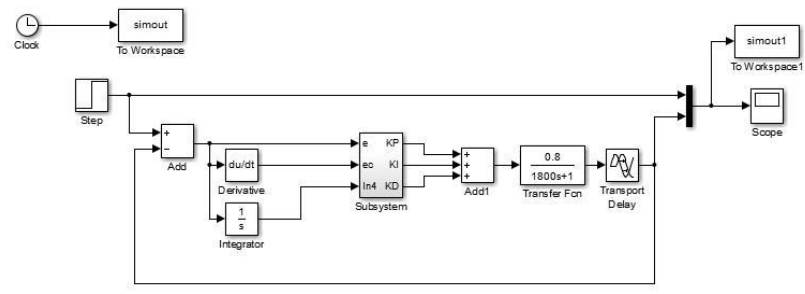

Figure 4. Simulation block diagram of fuzzy PID control system

The simulation time $\mathrm{T}$ is 3000 seconds, and the system of the fuzzy PID controller has two inputs and three outputs (Shown in Figure4).The subsystem is shown in Figure 5. The inputs are system deviation $\mathrm{E}$ and system deviation change rate EC (Gaussian membership function), and the outputs are $K_{p}, K_{i}, K_{d}$ (Triangle membership function), shown in Figure 6.

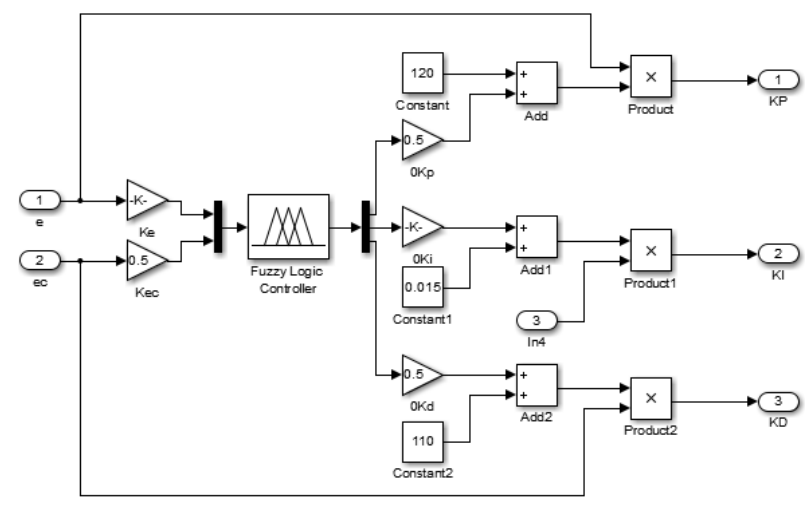

Figure 5. Subsystem of the fuzzy PID control
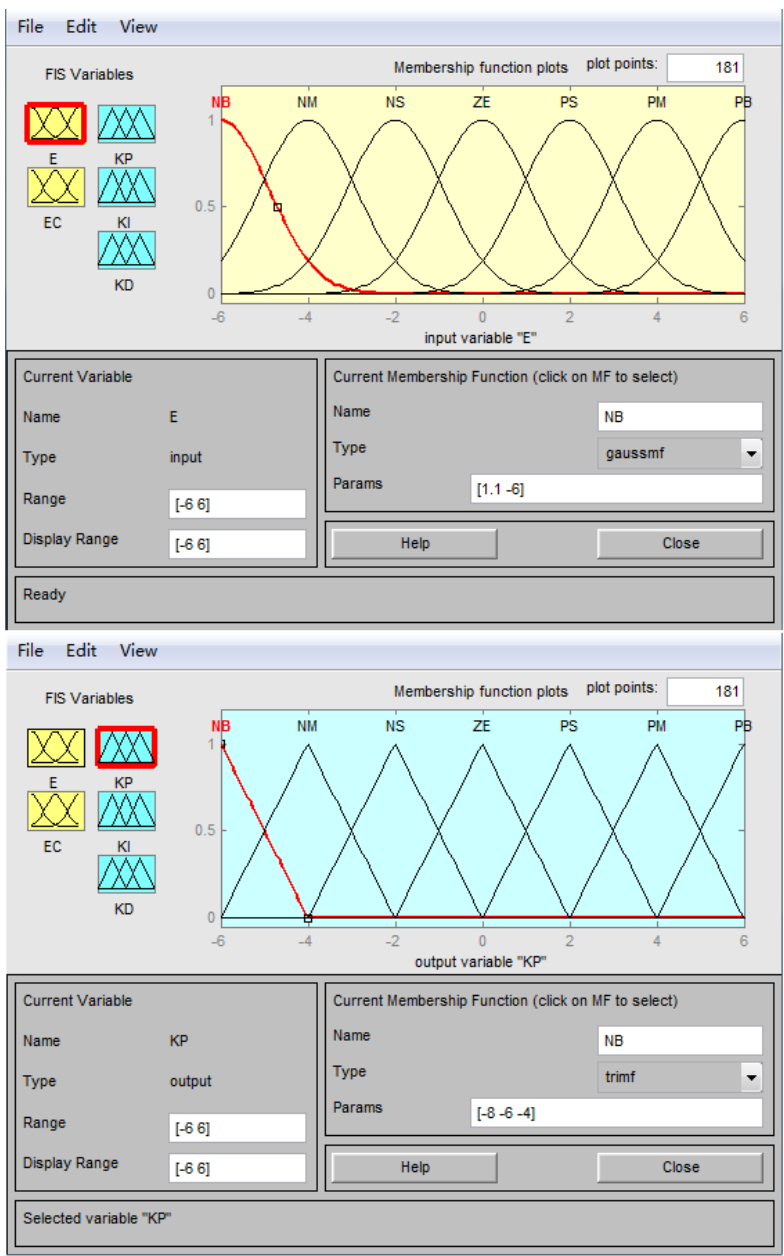

Figure 6. Membership function editor 


\section{B. Experiment result}

Figure 7 is the fuzzy PID control chart, and the results show that as for the large delay lag link, the fuzzy PID control has quicker response speed, small overshoot, and its control effect is good.

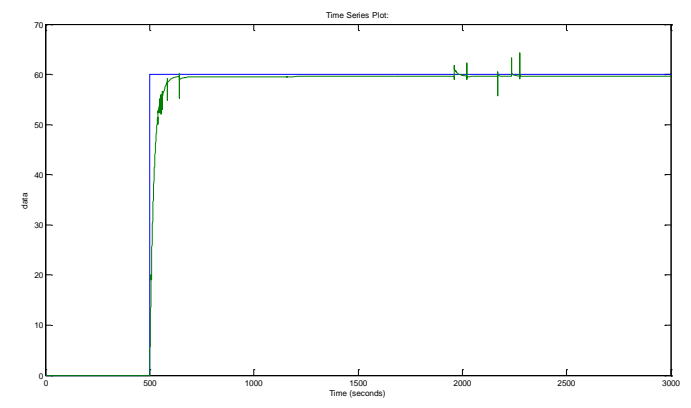

Figure 7. Fuzzy PID control output graph

\section{CONCLUSIONS}

In this paper, the design method of fuzzy controller and the realization of the fuzzy control method are analyzed based on the basic theoretical knowledge of fuzzy control, and the determination of membership function , fuzzy control rules, fuzzy PID controller design are introduced. Finally, a better experiment result has been acquired by checking the design of fuzzy controller with MATLAB simulation.

Fuzzy PID algorithm is used in this paper to control the object with pure time delay and time variation in the simulation, this algorithm realizes short response time, small overshoot, high control accuracy, and strong robustness. However, small glitch is still exist in the result, in order to get more accurate result, more date and parameter of the object or rule should be adjusted and redesigned.

\section{REFERENCES}

[1] Zadeh,L. A Fuzzy sets, Information Control,8,1965,94-102

[2] Chang,S.S.L. and Zadeh,L.A., "On fuzzy mapping and control," IEEE Transactions on Systems, Man and Cybernetics,SMC2,1972,30-34.

[3] Jikai Yi, "Intelligent control technology," Beijing: Beijing industrial university press, 1999.78-114.
[4] Mitra,S. and Pal,S.K., "Fuzzy self-organization, inferencing and rule generation," IEEE Transactions on Systems, Man and Cybernetics,26, 1996, pp. 608-620.

[5] Vidal-Verdu,F. and Rodriquez-Vazquez, A., "Using building blocks to design analog neuro-fuzzy controllers," IEEE Micro, 15 , pp. 49-57,August 1995

[6] Mitra,S. and Pal,S.K., "Fuzzy self-organization, inferencing and rule generation,'IEEE Transactions on Systems, Man and Cybernetics, 26, 1996, pp. 608-620.

[7] Lin, C.T. and Lu Y.C., "A neural fuzzy systems with fuzzy supervised learning," IEEE Transactions on Systems, Man and Cybernetics, 26, 1996, pp. 744-763.

[8] Pedrycz, W.,Poskar, C.H., and Czezowski, P.J., "A reconfigurable fuzzy neural network with in-situ learning," IEEE Micro, 15, August 1995, pp. 19-29.

[9] Tonshoff,H.K and Walter,A.,"Self-turning fuzzy-controller for process control in internal grinding,"Fuzzy Sets and Systems,63, 1994, pp. 359-373.

[10] QingJie Yang ,Guohou Li and Xusheng Kang, "Application of fuzzy PID control in the heating system," Control and Decision Conference, 2008, pp. 268.

[11] Huang, Y. and Yasunobu, S, "A general practical design method for fuzzy PID control from conventional PID control," Fuzzy Systems, 2000 , pp. 969 - 972 vol.2.

[12] Petrov, M. , Ganchev, I. and Taneva, A, "Fuzzy PID control of nonlinear plants," Intelligent Systems, 2002, pp. 30 - 35 vol.1.

[13] Wangbiao Qiu and Zhiyuan Qiu, "Design for temp-humidity control system of tobacco parching house based on Fuzzy-PID control," Mechatronics and Automation, 2006 , pp. 2229 - 2234.

[14] Wei Yang, Hui Liu , Shuo Zhang and Jingyu Liu, “The Simulation Research on Fuzzy PID Control Strategy of Commercial Vehicle EPS System,” Intelligent Systems (GCIS), 2010, pp. $237-240$.

[15] Gui-mei Cui , Peng Xiao and Ya-ni Li, "Based on the heating furnace temperature Fuzzy-PID control method research," Intelligent Control and Automation (WCICA), 2012 , pp. $1553-$ 1557.

[16] Aiping Shi, Maoli Yan, Jiangyong Li , Weixing Xu and Yunyang Shi, "The research of fuzzy PID control application in DC motor of automatic doors," Electrical and Control Engineering (ICECE), 2011 , pp. $1354-1358$.

[17] Wang Hui , Yang Yongbo and Liu Meiyu, "Fuzzy-PID Control in the Application of Multi-purpose Vehicles of the Road Snow Plowing," Web Information Systems and Mining, 2009, pp. 246 -250 .

[18] Keliang Zhou and Hongyan Yu, "Application of fuzzy predictivePID control in temperature control system of Freeze-dryer for medicine material," Mechanic Automation and Control Engineering (MACE), 2011, pp. 7200 - 7203.

[19] Ping Xue , Haichao Wang , Juanjuan Hou and Wenchao Li, "Based on the fuzzy PID brushless DC motor control system design," Measurement, Information and Control (MIC), 2012 , pp. $703-$ 706.

[20] Ma Fengying and Li Huanling, "Self-adaptive Fuzzy PID control algorithm used in liquid mixing device," Control and Decision Conference (2014 CCDC) 2014 , pp. 3840 - 3844. 